\title{
Etnocídio na Banda Oriental: A Resistência Étnica dos Charrua Perante a Colonização.
}

\author{
Etinocídio en la Banda Oriental: La Resistencia Étnica de los Charrua \\ Ante la Colonización.
}

\author{
Ethnocide in the Eastern Band: The Ethnic Resistance of Charrua to \\ Colonization.
}

\author{
Taciane Neres Moro ${ }^{1}$ \\ Ronaldo Bernadino Colvero ${ }^{2}$
}

\begin{abstract}
Resumo
Os Charrua eram povos originários que viviam no território que atualmente delimita a fronteira oeste do Estado do Rio Grande do Sul e também territórios que hoje delimitam os países da Argentina e Uruguai. Esse grupo indígena tinha uma cultura e forma de viver própria, no período da colonização, a partir do Séc. XVI essa cultura sofreu algumas transformações, no entanto, essa etnia conseguiu prevalecer a sua essência mantendo alguns padrões culturais distinto dos colonizadores, o que gerou o etnocídio e quase extermínio dos mesmos. Sendo assim, a presente pesquisa tem por objetivo analisar como os povos originários Charrua enfrentaram a colonização, como os mesmos conseguiram manter o seu modo de vida indígena absorvendo algumas novas práticas e principalmente, quais foram as razões que levaram o etnocídio dos charrua nas batalhas de Salsipuedes e Mataojos (1830-1834). Esse trabalho foi desenvolvido através da metodologia qualitativa, através da pesquisa bibliográfica em diferentes fontes como livros, artigos e dissertações.
\end{abstract}

Palavras-Chave: Charrua; Etnocídio; Território; Colonização.

\section{Resumen}

Los Charrúa eran pueblos originarios que vivían en el territorio que actualmente delimita la frontera oeste del Estado de Rio Grande do Sul y también territorios que hoy delimitan los países de Argentina y Uruguay. Este grupo indígena tenía una cultura y forma de vivir propia, en el período de la colonización, a partir del siglo XVI esa cultura sufrió algunas transformaciones, sin embargo, esa etnia logró prevalecer su esencia manteniendo algunos patrones culturales distinto de los colonizadores, lo que generó el etnocidio y casi exterminio de los mismos. Siendo así, la presente investigación tiene por objetivo analizar cómo los pueblos originarios Charrua se enfrentaron a la colonización, como los mismos lograron mantener su modo de vida indígena absorbiendo algunas nuevas prácticas y principalmente, cuáles fueron las razones que llevaron el etnocídio de los charrúa en las batallas Salsipuedes y Mataojos (1830-1834). Este trabajo fue desarrollado a través de la metodología cualitativa, a través de la investigación bibliográfica en diferentes fuentes como libros, artículos y disertaciones.

Palabras claves: Charrua; etnocidio; territorio; La colonización.

\begin{abstract}
The Charrua were native peoples who lived in the territory that currently delimits the western border of the State of Rio Grande do Sul and also territories that today delimit the countries of Argentina and Uruguay. This

\footnotetext{
${ }^{1}$ Acadêmica do curso Ciências Humanas - Licenciatura; Membro do grupo de pesquisa "Relações de Fronteira: História, Política e Cultura na Tríplice Fronteira Brasil, Argentina e Uruguai”; Bolsista de Iniciação Cientifica PDA - Extensão 2017. End. Eletrônico: tacianenmoro@ hotmail.com

${ }^{2}$ Prof ${ }^{\mathrm{o}}$ Dr. Da Universidade Federal do Pampa; Coordenador do grupo de pesquisa "Relações de Fronteira: História, Política e Cultura na Tríplice Fronteira Brasil, Argentina e Uruguai”
} 
indigenous group had a culture and way of living itself, in the period of colonization, from the 16th century this culture underwent some transformations, however, this ethnicity was able to prevail its essence maintaining some cultural patterns distinct from the colonizers, which generated ethnocídio and almost extermination of the same. Therefore, the present research has as objective to analyze how the native peoples Charrua faced the colonization, how they managed to maintain their native way of life absorbing some new practices and mainly, which were the reasons that led the ethnocídio of the charrua in the battles of Salsipuedes and Mataojos (18301834). This work was developed through the qualitative methodology, through bibliographical research in different sources such as books, articles and dissertations.

Keywords: Charrua; Ethnocide; Territory; Colonization.

\section{Introdução}

O presente artigo tem por objetivo realizar uma análise sobre a resistência étnica dos Charrua, grupo indígena que vivia no território do pampa, que atualmente delimita a fronteira dos países Brasil, Argentina e Uruguai.

Os Charrua são um grupo étnico que segundo Garcia \& Milder (2012) viviam em territórios próximos aos Minuanos, esses povos viviam em convergências e divergências, e por vezes foram confundidos como apenas um só grupo. Sendo assim será imprescindível durante o desenvolvimento desta pesquisa não citar algumas passagens da bibliografia de ambos os grupos, porem o enfoque a ser dado será apenas sobre a etnia Charrua.

Os Charrua se recusaram a viver sobre os moldes de vida dos colonizadores, porém, sem ter outras formas de sustento acabaram se tornando saqueadores das estâncias de gado e em algumas ocasiões coadjuvantes em guerras, por fim, em uma emboscada os Charrua foram friamente atacados sobrando poucos sobreviventes, esses, vendidos para a sociedade branca (VIDAL, 2009). Dito isto, se torna de extrema relevância para a historiografia da região desenvolver reflexões sobre o etnocídio em que os Charrua foram vítimas.

\section{Metodologia}

Essa pesquisa foi realizada através da metodologia qualitativa e como método, utilizamos o histórico através de uma discussão entre autores, nós conseguimos abordar a temática por diferentes olhares, que nos proporcionaram um conhecimento aprofundado e uma melhor abordagem.

O método histórico consiste em investigar acontecimentos, processos e instituições do passado para verificar sua influência na sociedade de hoje, mas como permanências e rupturas, pois as instituições alcançaram sua forma atual por meio de alterações de suas partes componentes ao longo do tempo, influenciadas pelo contexto cultural particular de cada época (LAKATOS, 2006, p. 91). 
Utilizando uma base historiográfica é constituído este trabalho, que utiliza este método nos momentos que necessitamos de descrever o processo histórico de resistência étnica dos Charrua, ao qual, para eles não existia a possibilidade de serem colonizados pelo homem branco, mantendo assim o modo de vida indígena, entretanto, os Charrua sofreram algumas alterações culturais da dinâmica territorial e espacial.

\title{
2.1. Características dos Charrua
}

Os povos Charrua são descendentes da Tradição Umbu, um dos primeiros grupos de seres humanos que ocuparam o território que delimita atualmente o estado brasileiro Rio Grande do Sul, em torno de $10.400^{3}$ anos A.P. Segundo Ribeiro (1997) os povos respectivos desta tradição são caracterizados como caçadores coletores generalizados, pois tinham uma base alimentar variada, o que garantia uma alimentação diversificada e propicia durante todo o ano. Ribeiro (1997) delimita o território que a tradição Umbu ocupava no:

\begin{abstract}
Uruguai e, esporadicamente, algumas áreas de Corrientes e Entre Rios, na Argentina... para o norte, até o nordeste do estado do Paraná e República do Paraguai; para o oeste, naquelas duas províncias argentinas mais a de misiones; ao leste, o Oceano Atlântico; ao sul, até o extremo sul da América, no estreito de Magalhães (RIBEIRO, 1997, p.103-104).
\end{abstract}

Ao longo dos anos a Tradição Umbu deu início a formação de dois grupos étnicos conhecidos pelos colonizadores a partir do século XVI como Charrua e Minuano. De acordo com Ítala Irene Becker (2006) uma das primeiras estudiosas sobre a cultura indígena, desses grupos pampeanos, ambos eram povos pré-coloniais construtores dos cerritos ${ }^{4}$, caçadores, coletores e pescadores.

Garcia \& Milder (2012) especificam a localidade dos Charrua e Minuano, sendo os primeiros a oeste do rio Uruguai, e os segundos a leste, devido a esse contexto geográfico, os Charrua tiveram contato primeiro com os jesuítas, e os Minuano com os portugueses. Ambos durante o final do Séc. XVII.

Segundo Becker (1982, p.73) através dos relatos de Pero Lopes de Sousa, Martin del Barco Centenera, Toribio Medina e André Thevet, os Charrua eram vistos como grandes e robustos, morenos, cabelos lisos e pretos e olhos castanhos, e com pouca pilosidade corporal, além de terem:

\footnotetext{
${ }^{3}$ Essa datação, conforme Ribeiro (1997, p. 108) diz respeito a fase Uruguai e Capivara.

4 "Os Cerritos são pequenas elevações do terreno, com forma aproximadamente circular, oval ou elíptica, compostos principalmente de terra, ou com grande quantidade de restos de alimentos humanos, que podem chegar até $100 \mathrm{~m}$ de diâmetro e $7 \mathrm{~m}$ de altura" (SCHMITZ, 2006, p.103)
} 
contornos perfeitos, e formas pouco pronunciadas, as cavidades dos órgãos principais bem desenvolvidas. Crânio dolicomorfo, frente reta e o ângulo facial bastante aberto. O rosto é oval com olhos pequenos e sobrancelhas delicadas, o nariz é um pouco aquilino e a boca pequena com o lábio inferior pouco extrovertido (BECKER, 1982, p.74 apud. POLAMCO, 1980).

Em relação à vaidade, os Charrua eram retraídos, e sem muita manifestação artística, também não havia o conceito de traição nas relações afetivas, assim, não tinham ciúmes de suas esposas, podendo inclusive haver poligamia:

\begin{abstract}
[...]eram também pouco ciumentos com relação às suas mulheres, que cediam com facilidade ao colonizador luso ou espanhol como forma passageira de negociação. Sua vaidade era expressa nas pinturas faciais diferenciadoras de tribo e nos homens, de modo especial, pelas cicatrizes intencionais estampadas no corpo numa correspondência ao número de inimigos mortos (BECKER, 2006, p.138).
\end{abstract}

Becker (2006) afirma que para os Charrua as mulheres podiam se relacionar com os homens assim que alcançassem a idade núbil, após o casamento as mulheres ficavam submissas aos seus parceiros. Já os homens poderiam assumir um relacionamento assim que adquirissem uma certa maturidade. As mulheres Charrua tinham que passar por uma cerimônia, no qual eram levadas para um toldo especifico sendo cobertas por agasalhos durante o ritual (Garcia \& Milder, 2012, p.3 apud Porto 1936). Garcia \& Milder (2012) ressaltam que o divórcio era muito comum entre os Charrua. Becker (2006) afirma que o sistema de criação dos filhos era de certa forma frouxa, não havia rotina fixa, as crianças faziam o que tinham vontade. Trata-se de um aspecto cultural diferenciado da qual a sociedade atual está familiarizada, por isso, é importante salientar que, para os Charrua não havia outro sistema de educação para os seus filhos, ou seja, para os Charrua, a forma que a autora descreveu, na perspectiva deles era o sistema adequado.

As formas de moradia eram basicamente por abrigos que as mulheres construíam nas aldeias, e ficaram conhecidos como "choça" (tolda). As aldeias eram organizadas e mantinham em boas relações, como salienta Becker:

Cada aldeia tinha o seu pequeno cemitério também localizado sobre uma coxilha próxima à aldeia que se transferia de acordo com a mobilização imposta aos grupos. Nos conflitos quase permanentes com o colonizador as aldeias se concentravam em espaços menores e se movimentavam como um todo com os seus caciques, pois eram raríssimas as desavenças entre os chefes índios (BECKER, 2006 p. 140).

Conforme Garcia \& Milder (2012), os toldos dos Charrua eram construídos para abrigar aproximadamente dez pessoas, ou seja, uma família inteira, sem distinção de sexo ou idade, e quando não havia mais espaço era construído outro toldo ao lado. E passaram a 
utilizar o couro bovino para adequar suas habitações como uso primordial a partir do Séc. XVII (GARCIA \& MILDER, 2012. Apud PORTO, 1954).

Em relação hábitos alimentares, de acordo com Garcia \& Milder (2012), os Charrua costumavam a se alimentar coletivamente fora de seus toldos. Segundo Becker (1982, p.80), até o séc. XVI a alimentação tinha como base a carne de variadas espécies de animais, mas era predominantemente a pesca do peixe, ambas atividades de pesca e caça era realizada pelos homens. Para a autora eles também complementavam a alimentação com a coleta de vegetais, e até esta época não havia a introdução da carne bovina como fonte de alimentação.

As suas organizações políticas inicialmente tinham base nos chefes de família, após, representantes do conselho da aldeia, que logo evoluíram para o cacicado. Os caciques tinham um importante papel de representação na aldeia perante a colonização, eram eles os responsáveis pelas negociações como o contrabando de gado e tratados de paz. Para se tornar um cacique o índio deveria ter pré-requisitos como audácia, valor moral e o consenso geral do grupo. (BECKER, 2006)

Os autores chamam a atenção para a utilização de tatuagens que era uma prática cultural muito comum dos Charrua e também dos Minuanos, sendo que os Charrua utilizavam uma espécie de argila escura sobre a pele picoteada. (GARCIA \& MILDER 2012 apud Cesar 1998).

Becker (2006) explica que os Charrua desenvolveram táticas de guerrilhas que foram muitos uteis para a sobrevivência, como a observação do inimigo, movimentação parcial de homens e cavalhadas, escolha do momento certo para o ataque, geralmente antes do amanhecer, e a fuga da família através da mata, onde o homem branco não conseguiria os encontrar.

De acordo com Viviane Vidal (2009) em sua dissertação de mestrado, dedicada a compreender as bolas de boleadeiras, uma das suas principais armas de caça, guerra e jogos dos Charrua e Minuano. A autora destaca que atualmente, estes artefatos muito utilizados com o gado selvagem e nas disputas indígenas por território perderam sua funcionalidade técnica no trabalho com o gado domesticado. Porém, continuam como elementos simbólicos na indumentária do homem do campo que os remete a memória pampeana (VIDAL, 2009).

A morte era entendida como um fato natural da vida, e não existia a possibilidade de deixar os mortos sem sepultamento, seus enterros eram em covas rasas, cobertas com pedras ou ramos, seus pertences como boleadeiras eram enterradas juntamente com o dono e "a lança ficava plantada no lado oposto ao qual deixavam o cavalo" (BECKER, 2006, p. 143). 


\subsection{Colonização, transculturação e resistência étnica dos Charrua}

O processo de colonização com os Charrua ocorreu de maneira diferente dos índios Guarani que foram catequizados nas Reduções Jesuítas. Os Charrua assim como os Minuano não se renderam a cultura do homem branco, mas adquiriu alguns costumes que ocasionou em uma transculturação. A partir do séc. XVI foram estabelecidas as primeiras relações com os colonizadores, através do gado equino e bovino. A partir do sec. XVII os jesuítas e os portugueses já buscavam colonizar a antiga banda oriental do Uruguai, como mostra a seguinte passagem:

diante desse quadro os Charrua e Minuano continuaram caçadores enquanto o colonizador não consegue, por si, ocupar e incorporar o território indígena. Aos poucos, nos séculos XVII e XVIII, o colonizador vai se fixando de forma lenta e cada vez mais para o interior do território índio. Primeiro se fixa no lado espanhol, ao lado do Rio Uruguai, em área dos Charrua; depois, no lado português, ao longo do litoral atlântico, em área dos Minuano (BECKER, 2006, p. 136).

Os Charrua eram constantemente solicitados pelos colonizadores para cuidar do gado no campo, tais negociações eram realizadas pelos caciques, e essa relação permitiu certo grau de respeito entre as duas culturas.

Com o passar do tempo, e o avanço da colonização a cultura dos Charrua foi se transfigurando. Os Charrua passam a se tornar pequenos criadores de gado, para manter relações de troca por objetos de satisfação pessoal, e principalmente para o próprio consumo, essa que se tornou a fonte mais requerida de alimentação (BECKER, 2006).

Becker (1982), destaca o uso do cavalo pelos Charrua e o consumo da carne bovina como as principais mudanças adquiridas após a colonização, com o cavalo, os Charrua conseguiam caçar o gado de forma segura e rápida. Logo, “os reflexos dessa transformação se fazem sentir em todos os aspectos da vida Charrua, mormente na alimentação, no vestuário, na casa, os gostos alimentares se refinam" (BECKER, 1982, p. 86).

Conforme a autora, a dependência desses índios perante os novos hábitos ocasionava seguidos roubos de gado das estâncias jesuíticas para serem comercializados com os portugueses. Como destaca Serres (2012) "Grupos indígenas, como os Charruas e Minuanos, faziam muitas irrupções nas estâncias missioneiras, o que gerava conflitos contínuos" (SERRES, 2012, p. 14).

Segundo Becker (2006), no final do Séc. XVIII os espanhóis e portugueses já estavam ocupando todo o território indígena, aumentam as estâncias de gado e a exportação de carne e couro passa a ser tanto interna quanto externa para a Europa. Os Charrua já estavam sem 
território, sendo obrigados a trabalhar para o homem branco. Para os Charrua eram oferecidos empregos como no mercado clandestino de couros, destinados para conflitos ou lutas por independência, ou em poucas opções se tornar peões de estâncias. Entretanto como a autora ressalta:

Essa alternativa de emprego é passageira porque fixada a independência política e não sendo mais necessário o trabalho do índio, os Charrua e Minuano passam a ser perseguidos insistentemente pelas forças governamentais para as quais trabalharam, lutaram e sacrificaram muitas vidas (BECKER, 2006, p. 138).

Por fim, de acordo com Becker (2006), o combate de extermínio de 1831 e 1832 os dois grupos foram praticamente destroçados em campo nas batalhas Salsipuedes e Mataojos, os homens que restaram vivos foram levados e sacrificados em Montevideo, às mulheres crianças e idosos foram levados para a capital distribuídos para a sociedade branca conforme suas exigências.

Conforme Vidal (2009 apud. ACOSTA \& LARA, 1961) o extermínio aconteceu no período pátrio II (1830-1834) sob comando do General Rivera que atuava também como presidente do Uruguai, as causas são em suma a resistência principalmente dos Charrua que resistiam em se modal na cultura europeia, e também aos importunos saques as estâncias.

Segundo Vidal (2009), as batalhas de Salsipuedes e Mataojos foram emboscadas para exterminar de vez com o grupo Charrua, Rivera estabeleceu uma falsa aliança com os indígenas para lutar em uma suposta guerra contra o Brasil, sendo assim os Charrua se deslocaram para Salsipuedes

Com o massacre de Salsipuedes, o General Rivera deu por vitorioso os objetivos da sua campanha, permitindo que as tropas do exército uruguaio que haviam participado do combate se reintegrassem aos seus postos. Algumas unidades foram licenciadas e outra, a mando do coronel Bernabé Rivera, saíram em busca do restante dos Charrua que haviam escapado do massacre. Em 27 de junho de 1832, o coronel Bernabé permitiu um choque armado aos Charrua, na barra de Mataojo com o Arepay, em que os Charrua, apesar da sua eficiência guerreira, tiveram quinze mortos e oitenta e dois prisioneiros, enquanto nas forças do governo uruguaio não foi registrada nenhuma baixa (VIDAL, 2009, p. 79).

No entanto, a etnia Charrua conseguiu sobreviver ao etnocídio das batalhas de Salsipuedes e Mataojos, Garcia \& Silva (2012) afirmam que uma aldeia Charrua foi reconhecida em 2007 “no Rio Grande do Sul como categoria categoria êmica/nativa sóciocosmológico-identitária pela Fundação Nacional do Índio (FUNAI)" (GARCIA e MILDER, 2012. Apud. SILVA, 2008).

Esse grupo reconhecido pela FUNAI afirma ser descendente direto dos sobreviventes de Salsipuedes, e conforme sua cacica Acuab, até a década de 1950, seus antepassados sobreviveram a partir de caça e coleta na região missioneira do Rio Grande do Sul, utilizando inclusive artefatos líticos. Atualmente esses Charrua estão estabelecidos no município de Porto Alegre, na aldeia Polidoro Povo Charrua, nome escolhido em homenagem ao celebre cacique de mesmo nome. Acuab nasceu em São Miguel das Missões, onde viveu até a morte dos pais, situação que a fez mudar-se com seus irmãos para a periferia de Porto Alegre. Acuab 
afirma possuir, fora de sua aldeia nos municípios de São Miguel das Missões, Santo Ângelo e São Borja, muitos outros parentes Charrua, com os quais periodicamente mantém contato (GARCIA; MILDER, 2012, p. 46)

Segundo Victória \& Neto (2011), o grupo Charrua sobrevivente atualmente vive em uma aldeia em uma extensão de terra concedida pelo governo municipal de Porto Alegre capital do Estado Rio Grande do Sul. Conforme os autores, apesar dos Charrua terem conseguido o espaço, ainda sofrem e precisam lutar por direitos básicos como água potável e recursos como medicações, além o constante descaso das autoridades governamentais responsáveis, ou seja, as lutas por condições básicas para sobrevivência ainda são presentes para essa etnia que tanto sofreu para conquistar os eu espaço.

\section{Conclusões}

Dada a análise da bibliografia, conclui-se que os Charrua conseguiram manter algumas principais características do seu modo de vida indígena, no entanto, como houve uma mudança na dinâmica territorial onde eles estavam inseridos (espaço que delimita fronteira Brasil, Argentina e Uruguai), foi inevitável a transculturação, alteração e intensificação em alguns hábitos.

Podemos destacar como já mencionado anteriormente, a atribuição a montaria do cavalo, o uso do coro bovino em vestimentas e nas "choças", as negociações com tanto com os portugueses quanto com os espanhóis, a intensificação pela preferência da carne na base alimentar, no qual a carne bovina se tornou a principal fonte de alimentação.

Essas mudanças geraram a dependência dos Charrua com o cavalo e o gado, logo, as invasões nas estâncias que antes eram promovidas pelo homem branco, com o tempo e a ocupação de toda extensão territorial, os roubos de gado se tornaram um problema. Esse contexto somado com a negação dos Charrua em viver nos padrões do homem branco ocasionaram as emboscadas de Salsipuedes e Mataojos. E mesmo com a sobrevivência e resistência de uma aldeia Charrua, essa etnia ainda sofre e precisa lutar por seus direitos básicos.

\section{Referências}

BECKER, Itala Irene Basile. O que sobrou dos índios pré-históricos do Rio Grande do Sul. p. 125-147. In. SCHMITZ, Pedro Ignácio. NAUE, Guilherme. BECKER, Ítala Irene Basile. PréHistória do Rio Grande do Sul. Instituto Anchietano de Pesquisas - UNISINOS São

Leopoldo, RS, Brasil. 2006 
BECKER, Itala Irene Basile. Os índios Charrua e Minuano na Antiga Banda Oriental. (Dissertação de Mestrado) PUC-RS.Porto Alegre, 1982. $315 f$.

COLVERO, Ronaldo. Região Missioneira: Palco de Rupturas e Continuidades. p.151-164. In. COLVERO, Ronaldo. MAURER, Rodrigo. Missões em Mosaico da interpretação à prática: um conjunto de experiências.

GARCIA, Anderson Marques. MILDER, Saul Eduardo Seiguer. Convergências e divergências: aspectos das culturas indígenas Charrua e Minuano. Vivencia Revista de Antropologia. N³9. 2012. Disponível em:

$<$ http://www.cchla.ufrn.br/Vivencia/sumarios/39/PDF_para_INTERNET_39/2_Anderson_Ma rques_Garcia_Saul_Eduardo_Seiguer_Milder.pdf> Acesso em: 14/10/2015.

GARCIA, Anderson Marques. MILDER, Saul Eduardo Seiguer. Particularidades Históricas e Culturais dos Charrua e dos Minuano do Pampa Sul-Americano. Estudos Históricos. CDHRPyB- Ano IV. Nº. Uruguay. Julho 2012.

GARCIA, Elisa F. Os Sete Povos Após a Conquista de 1801: Administração Portuguesa e Agencia Indígena. p. 163-172. In. COLVERO, Ronaldo. MAURER, Rodrigo. Missões em Mosaico da interpretação à prática: um conjunto de experiências.

LAKATOS, Eva Maria; MARCONI, Marina de Andrade. Metodologia científica. São Paulo: Atlas, 2006.

PANIAGUA, Edson. Fronteiras, Violência e criminalidade na região da Platina. O caso do município de Alegrete (1854-1864). 2013.

PORTO, Aurélio. História das Missões Orientais do Uruguai. Livraria Selbach. Porto Alegre. 1954

SCHMITZ, Pedro Ignácio. Migrantes da Amazônia: a tradição Tupiguarani. p. 31-64. In SCHMITZ, Pedro Ignácio. NAUE, Guilherme. BECKER, Ítala Irene Basile. Pré-História do Rio Grande do Sul. Instituto Anchietano de Pesquisas - UNISINOS São Leopoldo, RS, Brasil. 2006

SERRES, Helenize Soares. Estas Terras e Seus Donos: Políticas de espacialidade em La Cruz e no mundo guarani missioneiro (1629-1828). 2012. 225 F. (Dissertação de Mestrado). Universidade Federal de Pelotas. Pelotas RS.

VIDAL, Viviane Margareth Pouey. Os artefatos de arremesso dos campos da América Meridional: um estudo de caso das boleadeiras. 2009. 151f. Dissertação (Mestrado em História) - Faculdade de Filosofia e Ciências Humanas, Pontifícia Universidade Católica do Rio Grande do Sul, Porto Alegre. WARNIER, Jean-Pierre. Construire la culture matérielle: L'Homme qui pensait avec ses doigts. Paris: Presses universitaires de France, 1999.

VÍCTORA,Ceres Gomes. NETO, Antonio Leite Ruas. Querem matar os 'últimos Charrua': Sofrimento social e 'luta' dos indígenas que vivem na cidade. Revista ANTHROPOLÓGICAS, ano 15, vol.22(1): 37-59 (2011). Disponível em:< http://www.revista.ufpe.br/revistaanthropologicas/index.php/revista/article/view/222>. Acesso em: 11/10/2017 